\title{
ANÁLISE DOS CRITÉRIOS FORMAIS DE QUALIDADE EDITORIAL: A POLÍTICA DE CLASSIFICAÇÃO DE PERIÓDICOS CIENTÍFICOS A PARTIR DO QUALIS PERIÓDICOS
}

\author{
ANALYSIS OF FORMAL CRITERIA FOR EDITORIAL \\ QUALITY: THE POLICY FOR CLASSIFICATION OF \\ SCIENTIFIC JOURNALS FROM QUALIS PERIÓDICOS
}

\author{
Raphael Faria Vilas Boas a \\ Fhillipe de Freitas Campos ${ }^{\mathrm{b}}$ \\ Bianca Amaroc
}

\begin{abstract}
RESUMO
Introdução: O Qualis Periódicos é um sistema nacional utilizado para classificar a produção intelectual dos pesquisadores brasileiros vinculados aos Programas de PósGraduação (PPGs). Nesse sentido, é direta a relação entre o renome de determinado PPG e a estratificação recebida pelos periódicos científicos em que seus membros publicam. Objetivo: Dada a importância das classificações recebidas pelos periódicos a pesquisa tem como objetivo analisar os critérios de avaliação qualitativos mais recorrentes cobrados pelo Qualis Periódicos no evento de classificação correspondente ao Quadriênio 2013-2016 em todas as áreas do conhecimento vinculadas ao Colégio de humanidades. Metodologia: A pesquisa é de natureza Quali-quantitativa realizada a partir de levantamento documental. Os critérios de avaliação das áreas citadas foram compilados, tabulados e analisados. Resultados: Percebe-se uma falta de integração na criação das políticas de avaliação de periódicos entre as áreas da amostra que cria um quadro em que uma classe de critérios pode ser muito importante para algumas áreas e nada ou pouco importante para outras. Conclusões: Os critérios qualitativos se caracterizam pela universalidade dos seus propósitos, dizem respeito a questões gerais da ciência e perpassam todas as áreas do conhecimento. O cumprimento desses critérios ajuda a garantir a cientificidade dos conteúdos publicados o que torna imprescindível questionar se é possível avaliar a produção científica brasileira sendo que parte dessa produção pode não estar passando pelos processos que garantem sua cientificidade. Diante da questão se propõe à construção de um núcleo básico de critérios de avaliação qualitativos comuns para todas as áreas.
\end{abstract}

\footnotetext{
a Bacharel em Biblioteconomia pela Universidade de Brasília (UnB). Email: biblio.raphafaria@gmail.com.

b Bacharel em Biblioteconomia pela Universidade de Brasília (UnB). Email: fhillipefc80@gmail.com.

c Doutora em Linguística Aplicada pela Universidade Pompeu Fabra (Espanha). Coordenadora de Sistemas e Projetos do Instituto Brasileiro de Informação em Ciência e Tecnologia (IBICT). E-mail: lancededados@gmail.com
} 
Descritores: Avaliação. Qualidade de periódico. Qualidade editorial. Qualis Periódicos. Periódicos científicos.

\section{INTRODUÇÃO}

Analisar os periódicos científicos segundo critérios editoriais previamente estabelecidos é uma prática recorrente no seio da comunicação científica. Isso ocorre, principalmente, devido ao modelo brasileiro para concessão de recursos para pesquisa, uma vez que "[...] os autores são avaliados no ciclo da comunicação efetiva pelos artigos que publicam, mas os periódicos, como veículo que disseminam esses artigos, também são avaliados" (OLIVEIRA, 2017, p. 43).

Há vários estudos que apontam tanto as motivações quanto as dificuldades de pesquisadores, discentes e docentes de diversas áreas do conhecimento para eleger o periódico científico como veículo de divulgação dos resultados alcançados em suas pesquisas. Dentre esses estudos, podem ser destacados: Ferreira, Marchiori e Cristofoli (2009), nas áreas de Ciências da Comunicação e Ciência da Informação/Biblioteconomia; Araújo (2013), em relação aos docentes da área de Ciências Jurídicas da Universidade Federal do Paraná (UFPR) e; de Araújo e Miguel (2017), em relação aos discentes do Programa de Pós-Graduação em Direito da UFPR. Apesar de os resultados dos três estudos apresentarem variações, pode-se dizer que as motivações mais relevantes dizem respeito ao reconhecimento acadêmico/científico entre os pares e perspectiva de citação pelos mesmos, oportunidade de disseminar informações concebidas cientificamente, possibilidade de contribuir com novas frentes de pesquisa e facilidades associadas ao ambiente da internet. Por fim, destaca-se um dos pontos levantados por Araújo e Miguel (2017, p. 48), no qual "cumprir com as exigências do Programa de Pós-Graduação do qual faço parte" foi a motivação tida como a mais importante por parte dos respondentes para publicar em periódicos, deixando claro o peso que esse veículo exerce no âmbito acadêmico/científico. Entre as dificuldades/limitações, os estudos apontam a baixa disponibilidade de tempo livre para conciliar pesquisa e docência com a escrita, demora do processo de avaliação por pares, a alta "concorrência" pelos 
periódicos de maior prestígio e o fato de boa parte da literatura especializada ser em outros idiomas.

A exigência para que os pesquisadores, em especial àqueles ligados aos PPGs, submetam suas pesquisas a determinados periódicos em detrimentos de outros está diretamente relacionada à ideia de prestígio da ciência, explanada por Costa (2018). Em seu trabalho, a autora objetivou investigar quais são os periódicos escolhidos pelos bolsistas de produtividade em pesquisa do Conselho Nacional de Desenvolvimento Científico e Tecnológico (CNPq), categoria 1A, para publicarem os resultados de suas pesquisas. Neste contexto, e utilizandose dos conceitos de campo, capital e habitus, a autora aponta que há uma relação direta entre os periódicos que determinados autores publicam suas pesquisas e o prestígio científico que lhes é concedido. Esse acúmulo de reconhecimento entre os pares reflete na posição dos acadêmicos na hierarquia da ciência, fazendo com que a disputa pelos periódicos com alto reconhecimento seja cada vez mais acirrada. Nesse sentido, e apesar da pesquisa ter estudado uma pequena e já prestigiada parcela da comunidade científica brasileira, as considerações da autora são relevantes para entender a lógica adstrita ao processo de comunicação científica.

Além dessas questões que envolvem, de maneira particular, os autores, ainda há de se ressaltar as problemáticas apresentadas entre os editores científicos e as plataformas indexadoras, em especial no contexto brasileiro. Tais dificuldades não são questões recentes e dizem respeito, especialmente, à ausência de boa parte dessas publicações nas principais plataformas indexadoras, como, por exemplo Scopus e Web of Science. Há duas décadas, Mueller (1999) já apontava que:

[...] para ser lido e citado, um artigo precisa ser encontrado pelo leitor. Os instrumentos de busca são os índices e periódicos de resumo ou bases de dados bibliográficas especializadas. Mas apenas os periódicos mais prestigiosos são sistematicamente analisados e incluídos nos índices e periódicos de resumo e nos índices de citação internacionais [...] Essas bases de dados, adotadas internacionalmente como fonte de referência para medir citações e impacto de artigos, autores e títulos, incluem apenas uma percentagem muito pequena de títulos provenientes dos países em desenvolvimento (MUELLER, 1999, n. p). 
Frente à afirmação de Mueller (1999), fica notório que os estudos em torno dos critérios aferidos durante a avaliação dos periódicos se mostram sempre relevantes, uma vez que possibilitam aos gestores das publicações adequarem os periódicos às principais normas exigidas pelos diversos indexadores e avaliadores, nacionais e internacionais.

Outra questão essencial a ser discutida diz respeito às mudanças advindas da ascensão dos periódicos eletrônicos, uma vez que esse tipo de suporte introduziu uma série de problemáticas que antes, no formato de publicação impresso, sequer eram consideradas. Dentre as mudanças advindas, podem ser citadas, de modo especial, aquelas relacionadas a:

[...] aplicação de textos em formato HTML e PDF, de ferramentas de busca, de ferramentas interativas (e-mail, formulários), do contador de acessos, de instruções de uso do site, da presença de logotipo de identificação do editor, de políticas de preservação online (armazenamento, recuperação e disseminação) e da multiplicidade de suportes (impresso e CDROM) (PASSOS et al., 2018, p. 216).

Diante às questões expostas, percebe-se que a editoração de periódicos científicos é uma atividade permeada de problemáticas que nem sempre são de conhecimento dos editores, fazendo com que muitas das publicações não alcancem níveis mínimos de qualidade do ponto de vista editorial.

Voltando-se de forma mais específica para a validação da produção brasileira a Coordenação de Aperfeiçoamento de Pessoal de Nível Superior (Capes), fundação vinculada ao Ministério da Educação (MEC), sempre teve um papel central no que diz respeito à avaliação e a atribuição de credibilidade à produção científica. A Capes é a entidade responsável por avaliar e chancelar os Programas de pós-graduação (PPGs) stricto sensu (mestrado e doutorado) $e$, dentre suas competências, está a de estratificar a qualidade da produção intelectual dos docentes e discentes dos programas, majoritariamente representada pelas publicações em periódicos científicos. O Qualis Periódicos é a instância da Capes responsável pela avaliação dos periódicos, é um sistema nacional que avalia os periódicos científicos utilizados como plataforma de publicação pelos pesquisadores ligados aos PPGs de instituições brasileiras. A Capes pontua assim os PPGs com base na qualidade dos periódicos em que 
seus pesquisadores estão publicando. A análise envolvendo os periódicos não tem um fim em si mesmo, pois seu objetivo é qualificar os PPGs vigentes no Brasil.

O Qualis Periódicos é constituído por 49 áreas temáticas de avaliação que, por fins de organização, são agregadas em 9 grandes áreas que integram o "Colégio de Ciências da Vida", o "Colégio de Humanidades" e o "Colégio de Ciências Exatas, Tecnológicas e Multidisciplinar". Já no que tange aos aspectos de condução dos trabalhos de avaliação, "[...] são designados coordenadores para cada área, que, a cada período de avaliação, terão o papel de coordenar, planejar e executar as atividades das respectivas áreas junto a Capes [...]" (NOBRE; FREITAS, 2017). O processo de avaliação se dá, atualmente, por eventos quadrienais, sendo que o último evento finalizado se realizou no quadriênio 2013-2016. No evento de classificação de 2013 a 2016 a classificação dos periódicos se deu a partir de oito diferentes classes (A1, A2, B1, B2, B3, B4, $B 5$ e $C$ ), sendo a classe $A 1$ a mais criteriosa, e que confere a revista maior credibilidade, e a classe $C$ a menos criteriosa (NOBRE; FREITAS, 2017; SOMA; ALVES; YANASSE, 2016). Os critérios de avaliação são designados por cada área temática de maneira que podem ter ou não alguma relação com os critérios de uma outra área, os critérios variam, também, dentro de cada área para as diferentes estratificações. Frente às questões suscitadas e que envolvem, em um contexto mais amplo, a comunicação científica, e, em um contexto mais restrito, os periódicos científicos, é crucial que sejam feitas análises em relação aos critérios para definir as estratificações recebidas a partir do Qualis Periódicos.

Os critérios de avaliação podem ser divididos, de maneira geral, em critérios qualitativos ou formais que se voltam para a apresentação editorial e descrição da política da revista e os critérios quantitativos e bibliométricos que se relacionam como índices de citação e fatores de impacto. Oliveira (2017) aponta que, atualmente, há dois vieses distintos que podem ser seguidos para analisar os periódicos: o primeiro, qualitativo, focado na gestão editorial, e o segundo, quantitativo, focado em resultados e impacto na comunidade a que é destinado. Os critérios quantitativos são medidos por plataformas independentes 
da Capes como por exemplo o índice de citação "Índice H" (H-Index) da Google ou fator de impacto "Journal Citation Reports" (JCR) da Thomson Reuters. Em relação aos critérios quantitativos cabe às áreas apenas à escolha da plataforma que se adapta melhor as especificidades do seu tema, já para os critérios qualitativos as áreas podem tanto designar indexadores que avaliem aquilo que área considera importante, quanto criar os próprios critérios para a área. $\mathrm{O}$ presente estudo se volta assim para os critérios qualitativos, já que não é objetivo deste estudo analisar critérios de avaliação determinados por outras plataformas que não o Qualis Periódicos, pelo menos não de forma intrínseca, os indexadores serão relacionados somente à medida que são exigidos como critérios de meta avaliação. Barata (2016) e Oliveira (2017) apontam que a adoção de critérios formais é uma saída mais justa para avaliar os periódicos científicos e as áreas que fazem parte do "Colégio de Ciências da Vida" e do "Colégio de Ciências Exatas, Tecnológicas e Multidisciplinar" tendem, de maneira predominante, a construir a classificação considerando as bases de indexação e as medidas de impacto bibliométrico. Sendo assim, optou-se por limitar a pesquisa às 18 áreas do conhecimento vinculadas ao Colégio de Humanidades.

\section{OBJETIVO}

A avaliação da qualidade editorial de periódicos científicos é relevante para a avaliação da própria produção científica, pois remete a questões de acessibilidade, interoperabilidade, preservação, internacionalização, usabilidade, transparência e, mais enfaticamente, a cientificidade da produção publicada. Como indica Rozemblum (2015) a avaliação qualitativa de revistas cientificas não é infalível na garantia da cientificidade dos conteúdos publicados, mas são um passo necessário para se inibir práticas antiéticas. Relaciona-se, dessa forma, que o não cumprimento de determinados critérios de qualidade, que em geral concernem à ciência como um todo, pode por em questão a própria cientificidade das revistas avaliadas. Considerando as relações e assertivas que até aqui foram postas, este estudo 
objetiva analisar os critérios formais de qualidade editorial adotados pelo Qualis Periódicos para 18 áreas do conhecimento vinculadas ao Colégio de Humanidades, e, assim, fazer um diagnóstico da adoção desses critérios e da importância da sua adoção para a comunicação cientifica e para 0 desenvolvimento da ciência.

\section{METODOLOGIA}

Quanto à abordagem a pesquisa é quali-quantitativa. Qualitativa pois pretende compreender e explicar a dinâmica das relações estabelecidas e quantitativa já que a coleta de dados visa a obtenção de dados numéricos/frequências das fontes analisadas. Quanto à natureza, caracteriza-se como aplicada, pois, além de propor-se à aplicação prática, poderá solucionar problemas específicos de determinado grupo. Em relação aos objetivos, qualifica-se como descritiva e explicativa, uma vez as descrições dos dados apresentados pressupõem a necessidade de descrevê-los ao leitor. Por fim, quantos aos procedimentos metodológicos, a pesquisa é documental, devido 0 levantamento dos documentos de área divulgados pela Capes (SILVEIRA; CÓRDOVA, 2009).

Definidos os procedimentos a serem seguidos, a pesquisa foi fragmentada de forma que a manipulação dos dados pudesse ser realizada com maior nível de confiança e precisão possível. Para a análise dos dados, foi decidido considerar os critérios de avaliação adotados pela avaliação do quadriênio 2013-2016. Foram compilados critérios de avaliação das 18 áreas que compõem o Colégio de Humanidades descritos nos documentos "Considerações sobre o Qualis Periódicos" e "Relatório sobre o Qualis Periódicos" de cada área1. Nessa etapa, os esforços foram direcionados a sintetizar, em uma única tabela, os critérios comuns às 18 áreas, de forma que se chegasse a uma única listagem. Feito isso, passou-se a destrinchar cada um dos critérios requeridos de forma que, ao final, cada um deles se

\footnotetext{
1 Os documentos referidos se encontram no endereço:

https://www.capes.gov.br/avaliacao/sobre-as-areas-de-avaliacao.
} 
referisse a um único quesito. Esse trabalho foi necessário dado que o texto original dos critérios de avaliação tende a agregar duas ou mais exigências em um único tópico, o que pode gerar interpretações dúbias. A desambiguação dos textos originais gerou um total de 153 critérios de qualidade editorial. Os critérios que se repetiam em mais de uma área foram unificados, sendo atribuída a cada um deles uma frequência entre as 18 áreas do conhecimento. Em seguida, foi feita a distribuição de cada um em 38 classes distintas, as quais buscaram aglutinar critérios que compartilham características semelhantes. A partir de então foi possível extrair os dados finais da pesquisa e realizar análises sobre eles, as quais serão apresentadas mais adiante. É importante ressaltar que todo o processo de compilação, tabulação e análise dos dados foi realizado utilizando o software Excel, uma vez que nele foi possível calcular as frequências dos critérios e gerar representações gráficas deles.

\section{RESULTADOS}

O aprofundamento da discussão que se segue em torno dos resultados da pesquisa visa cumprir, primordialmente, ao objetivo geral apresentado anteriormente.

Tabela 1 - Representatividade das áreas em relação à totalidade de critérios

\begin{tabular}{|l|c|c|}
\hline \multicolumn{1}{|c|}{ Representatividade das áreas Qualis Capes } & Critérios & Porcentagem \\
\hline CRITÉRIOS QUALIS UNIFICADOS & 154 & 100 \\
\hline CIÊNCIA DA RELIGIÃO E TEOLOGIA & 54 & 35,06 \\
\hline LETRAS, LINGUÍSTICA E LITERATURA & 52 & 33,77 \\
\hline ANTROPOLOGIA & 52 & 33,77 \\
\hline HISTÓRIA & 48 & 31,17 \\
\hline SOCIOLOGIA & 47 & 30,51 \\
\hline COMUNICAÇÃO E INFORMAÇÃO & 42 & 27,27 \\
\hline EDUCAÇÃO & 40 & 25,97 \\
\hline DIREITO & 36 & 23,38 \\
\hline
\end{tabular}




\begin{tabular}{|l|c|c|}
\hline ARQUITETURA, URBANISMO E DESIGN & 36 & 23,37 \\
\hline ARTES & 33 & 21,43 \\
\hline ADMINISTRAÇÃO & 30 & 19,48 \\
\hline SERVIÇO SOCIAL & 26 & 16,88 \\
\hline CIÊNCIA POLÍTICA & 25 & 16,23 \\
\hline PSICOLOGIA & 23 & 14,94 \\
\hline $\begin{array}{l}\text { PLANEJAMENTO URBANO, REGIONAL E } \\
\text { DEMOGRAFIA }\end{array}$ & 23 & 14,94 \\
\hline GEOGRAFIA & 20 & 12,98 \\
\hline FILOSOFIA & 19 & 12,34 \\
\hline ECONOMIA & 9 & 5,84 \\
\hline
\end{tabular}

Fonte: Dados da pesquisa

A Tabela 1 apresenta, tomando por base a compilação de todos os critérios levantados, a quantidade de critérios requerida por cada uma das áreas do conhecimento. A unificação dos critérios que se encontram nas 18 áreas do Colégio de humanidades do Qualis Periódicos gerou um total de 153 critérios únicos, ou seja, não repetitivos, o que corresponde a $100 \%$ dos critérios analisados nesta pesquisa. As frequências apresentadas por áreas de conhecimento representam a quantidade de critérios que aquela área exige em relação ao total. A área do conhecimento "Ciências da religião e teologia" é a que exige maior número de critérios em sua avaliação, 54 dos 154 critérios encontrados, o que representa $35,06 \%$ do total. "Letras, linguística e literatura" e "Antropologia" são áreas que possuem, também, grande quantidade de critérios, figurando, cada uma, com 52 dos 153 critérios encontrados. A área "Economia" apresenta menor representatividade da amostra, exigindo somente nove critérios editoriais em sua avaliação. Na prática, a tabela mostra o quão exaustiva uma área é em relação às questões relacionadas à avaliação da qualidade editorial das revistas. 


\section{Gráfico 1 - Percentual de frequência dos critérios}

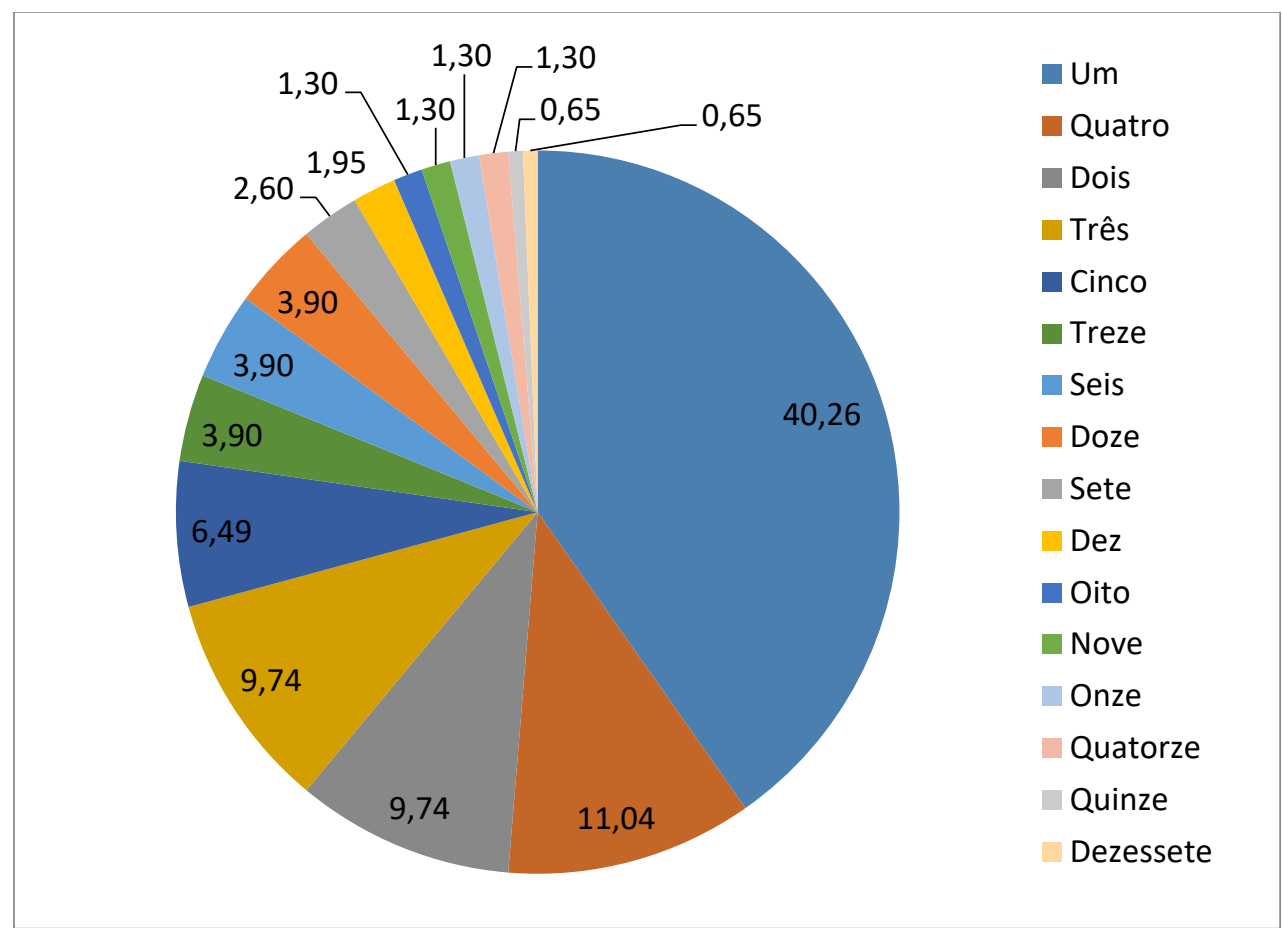

Fonte: Dados da pesquisa

O Gráfico um traz a frequência dos critérios de avaliação entre o total dos critérios encontrados em todas as áreas do conhecimento, ou seja, explicita quantas vezes aparece cada um dos 153 critérios. Extrai-se do gráfico que, entre os 153 critérios encontrados, 40,26\% (62) deles só aparecem em uma única área. Por outro lado, são poucos os critérios que se repetem em muitas áreas do conhecimento, de forma geral, progressivamente diminui-se o número de critérios a medida que se aumenta o número de áreas em que esses critérios se repetem. Ressalta-se que nenhum dos critérios levantados se repete nas 18 áreas, e que apenas um critério aparece em 17 delas. Essa dispersão demonstra haver certa discordância entre as áreas do conhecimento, que determinam seus critérios de avaliação de forma autônoma. Ao mesmo tempo, percebe-se que 92 critérios $(59,74 \%)$ figuram em mais de uma área temática, o que demonstra, por mais fraca que seja essa integração, alguma influência do trabalho de uma área sobre a outra. De todo modo, sabe-se que alguns critérios podem ser ignorados por determinadas áreas tendo em vista o não cumprimento dele pelas revistas da área ou, também, por ele ser dotado de certa "obrigatoriedade tácita", o que 
pode dar a entender aos comitês que definem os critérios que sua exigência explícita é desnecessária. Como exemplo disso, podemos citar a atribuição do código ISSN e a obrigatoriedade de realização da avaliação por pares.

\section{Quadro 1 - Critérios por frequência}

\begin{tabular}{|c|c|c|c|}
\hline № & $\begin{array}{l}\text { CLASSIFICAÇÃO DOS } \\
\text { CRITÉRIOS }\end{array}$ & $\begin{array}{l}\text { UNIFICAÇÃO DOS CRITÉRIOS } \\
\text { QUALIS }\end{array}$ & FREQUÊNCIA \\
\hline 1 & ISSN & Ter registro de ISSN; & 17 \\
\hline 2 & Corpo Editorial & $\begin{array}{l}\text { Apresentar listagem com o nome } \\
\text { todos os membros do corpo editorial; }\end{array}$ & 15 \\
\hline 3 & Avaliação por pares & $\begin{array}{l}\text { Ter processo de arbitragem por } \\
\text { pares; }\end{array}$ & 14 \\
\hline 4 & Normas de Submissão & Apresentar normas de submissão; & 14 \\
\hline 5 & $\begin{array}{l}\text { Bases de dados, indexadores e } \\
\text { índices }\end{array}$ & $\begin{array}{l}\text { Presença em ao menos } 1 \text { base de } \\
\text { dados, nacional ou internacional, e } \\
\text { que esteja disponível online; }\end{array}$ & 13 \\
\hline 6 & Cobertura temática & Informar cobertura temática; & 13 \\
\hline 7 & Corpo Editorial & Ter editor responsável; & 13 \\
\hline 8 & Cumprimento da periodicidade & $\begin{array}{l}\text { A publicação dos fascículos deve ser } \\
\text { pontual, de acordo com a } \\
\text { periodicidade declarada; }\end{array}$ & 13 \\
\hline 9 & $\begin{array}{l}\text { Informações gerais sobre } \\
\text { política editorial }\end{array}$ & Indicar política editorial; & 13 \\
\hline 10 & Resumo & Apresentar resumo em português; & 13 \\
\hline 11 & Afiliação dos autores & $\begin{array}{l}\text { Apresentar afiliação institucional dos } \\
\text { autores; }\end{array}$ & 12 \\
\hline 12 & Indicação da periodicidade & Indicar periodicidade; & 12 \\
\hline 13 & $\begin{array}{l}\text { Informações gerais sobre } \\
\text { política editorial }\end{array}$ & $\begin{array}{l}\text { Apresentar datas de submissão e } \\
\text { aprovação do artigo; }\end{array}$ & 12 \\
\hline 14 & Palavras-chave & $\begin{array}{l}\text { Apresentar palavras-chave em } \\
\text { português; }\end{array}$ & 12 \\
\hline 15 & Resumo & $\begin{array}{l}\text { Apresentar resumo em um segundo } \\
\text { idioma, prioritariamente em inglês; }\end{array}$ & 12 \\
\hline 16 & Exogeneidade do corpo editorial & $\begin{array}{l}\text { Corpo editorial composto por } \\
\text { pesquisadores vinculados a } \\
\text { diferentes instituições; }\end{array}$ & 11 \\
\hline 17 & Palavras-chave & $\begin{array}{l}\text { Apresentar palavras-chave em um } \\
\text { segundo idioma, prioritariamente em } \\
\text { inglês; }\end{array}$ & 11 \\
\hline 18 & $\begin{array}{l}\text { Afiliação dos membros do corpo } \\
\text { editorial }\end{array}$ & $\begin{array}{l}\text { Apresentar, por extenso, nome } \\
\text { completo das instituições as quais os } \\
\text { membros do corpo editorial são } \\
\text { afiliados; }\end{array}$ & 10 \\
\hline
\end{tabular}




\begin{tabular}{|l|l|l|c|}
\hline $\mathbf{1 9}$ & Periodicidade mínima & $\begin{array}{l}\text { A periodicidade mínima da revista } \\
\text { deve ser semestral; }\end{array}$ & 10 \\
\hline $\mathbf{2 0}$ & $\begin{array}{l}\text { Publicações de natureza } \\
\text { acadêmica/científica }\end{array}$ & $\begin{array}{l}\text { Conter publicações oriundas de } \\
\text { pesquisa com caráter } \\
\text { acadêmico/científico; }\end{array}$ & 10 \\
\hline $\mathbf{2 1}$ & Exogeneidade dos autores & $\begin{array}{l}\text { Pelo menos } 60 \% \text { dos artigos devem } \\
\text { ser de autores afiliados a instituições } \\
\text { diferentes da responsável pela } \\
\text { edição do periódico; }\end{array}$ & 9 \\
\hline $\mathbf{2 2}$ & Página web da revista & $\begin{array}{l}\text { A revista deve ser eletrônica, com } \\
\text { acesso online; }\end{array}$ & 9 \\
\hline
\end{tabular}

Fonte: Dados da pesquisa

O Quadro um traz, por frequência, o ranking dos critérios mais cobrados pelas áreas do conhecimento e é apresentado com vistas a explicitar, de modo mais categórico, alguns dos critérios cobrados. Como já dito, a quantidade de critérios levantada e de classes definidas são maiores do que ora apresentada, no entanto, como não é possível apresentá-las integralmente, optou-se por fazer uma seleção e apresentar de forma concisa. Apresentam-se no quadro 22 critérios de qualidade editorial e que se repetiram em, ao menos, nove áreas de avaliação². Nenhum dos critérios compilados encontra-se nas 18 áreas que fazem parte da análise, e esse fato, quando atrelado ao número de critérios que atendem a apenas uma área $(40,26 \%)$, corrobora com o indicativo de não existir coesão entre as áreas de avaliação do Qualis Capes a respeito dos critérios de avaliação adotados.

O critério de avaliação que mais é recorrente entre áreas e que, consequentemente, tem maior apreço na visão conjunta desses, é "Ter registro de ISSN", que é adotado por 17 áreas de avaliação. Na segunda colocação apresenta-se o critério "Apresentar listagem com o nome de todos os membros do conselho editorial", adotado por 15 áreas, e, em terceiro lugar, os critérios "Ter processo de arbitragem por pares" e "Apresentar normas de submissão", adotados por 14 áreas de avaliação. Tem-se, assim, que, das 18 áreas de avaliação, uma não adota o critério "Ter registro de ISSN", três não adotam o

2 O recorte da frequência foi feito considerando o número total de áreas do conhecimento estudadas na pesquisa (18). Sendo assim, foi escolhido repetição em ao menos nove áreas, o que significa metade das áreas estudadas. 
critério "Apresentar listagem com o nome todos os membros do corpo editorial", quatro áreas não adotam o critério "Ter processo de arbitragem por pares" e outras quatro áreas não adotam o critério "Apresentar normas de submissão". À primeira vista, salta aos olhos o fato de existirem áreas que não adotam critérios tão essenciais aos periódicos científicos, como, por exemplo, "Ter processo de arbitragem por pares". No entanto, isso não significa necessariamente que a área não faz a avaliação por pares, pois ela pode adotar outro critério que exija tal atividade, o que será analisado com maior nível de detalhes adiante.

Foram selecionados cinco critérios ("Ter registro de ISSN", "Ter processo de arbitragem por pares", "Corpo editorial composto por pesquisadores vinculados a diferentes instituições", "Conter publicações oriundas de pesquisa com caráter acadêmico/científico" e "Pelo menos $60 \%$ dos artigos devem ser de autores afiliados a instituições diferentes da responsável pela edição do periódico") para fazer uma análise mais detalhada de sua adoção ou não pelas áreas de avaliação. Esses critérios foram escolhidos por se reportarem às noções mais essenciais no que se refere à idoneidade da comunicação científica.

O critério 3 - "Ter processo de arbitragem por pares" - não é adotado por quatro áreas, sendo elas: "Arquitetura, Urbanismo e Design", "Direito", "Ciência política" e "Filosofia". Tendo em vista que a avaliação por pares é uma etapa essencial para a determinação do caráter científico dos artigos publicados em periódicos, faz-se necessária uma análise mais acurada acerca do comportamento das quatro áreas supracitadas acerca deste processo. Analisando a tabela em sua completude, tem-se que as áreas "Direito", "Ciência política" e "Filosofia" adotam o critério "Ter processo de arbitragem duplo-cega por pares" como forma de avaliação. Já a área "Arquitetura, Urbanismo e Design" - considerando o documento da área utilizado para este estudo - adota nenhum dos três critérios ${ }^{3}$ que compõem a classe "Avaliação por pares". Apesar da não cobrança explícita dos critérios incluídos nessa classe, não é possível fazer nenhum tipo de inferência que dê a entender que as revistas da área não fazem avaliação por pares. Há possibilidade do comitê responsável pela definição dos

\footnotetext{
${ }^{3}$ São critérios incluídos na classe: "Ter processo de arbitragem por pares", "Ter processo de arbitragem dupla-cega por pares" e "Especificação das normas de avaliação".
} 
critérios - pelo menos à época da elaboração do documento utilizado nesta pesquisa - ter considerado que a avaliação por pares é tão essencial que não seria necessário incluí-la explicitamente no documento. De todo modo, é altamente recomendado que o critério seja incluído nos documentos subsequentes, uma vez que a ausência dele pode abrir precedentes para periódicos da área não realizarem o processo de avaliação, em especial aqueles de baixa qualidade.

O critério 1 - "Ter registro de ISSN" - somente não é adotado pela área "Filosofia", pelo menos não de acordo com o documento de área levantado para esta pesquisa. O registro de ISSN é uma espécie de identidade de um periódico, uma vez que o identifica e difere de qualquer outro. Ter registro na rede ISSN traz uma série de indicativos acerca da revista, tais como: se é avaliada e identificada como publicação periódica; que a periodicidade se relaciona a uma publicação única e não outra com título similar; que os artigos não estão sendo publicado a esmo, e que, portanto, estão sob a responsabilidade de um ente catalogado e identificado na rede ISSN dentre outras questões. A não adoção do critério talvez possa ser explicada pela preponderância de revistas que fazem parte da rede ISSN, o que pode ter levado a área considerar esse critério como pré-requisito tácito ${ }^{4}$ de avaliação, o que não impede que uma publicação sem ISSN atribuído possa receber alta pontuação, já que o critério não foi previsto na política de avaliação.

O critério 17 - "Corpo editorial composto por pesquisadores vinculados a diferentes instituições" - é exigido por 11 das 18 áreas de avaliação, sendo as áreas que não o adotam: "Ciência da religião e Teologia", "Ciência política", "História", "Psicologia", "Economia", "Planejamento urbano, regional e Demografia" e "Serviço social". Avaliar a exogeneidade do corpo editorial é uma das principais maneiras de evitar que autores de determinada instituição sejam avaliados por pesquisadores da mesma instituição, que, por sua vez, muito

\footnotetext{
4 Para efeitos de comprovação, foi feita uma consulta à Plataforma Sucupira para verificar a atribuição ou não do código ISSN aos periódicos avaliados na área de Filosofia. De fato, não foi encontrado qualquer periódico avaliado na área - em todos os estratos de classificação que não tenha código de ISSN atribuído, o que tende a diminuir o impacto da não adoção deste critério.
} 
provavelmente fazem parte do mesmo Programa de pós-graduação e/ou grupo de pesquisa. A exogeneidade do corpo editorial permite - além do cumprimento de uma questão ética da publicação - que a edição da revista seja feita de forma diversificada inclusive do ponto de vista ideológico, uma vez que contará com pesquisadores com perspectivas e realidades distintas sobre uma mesma área de pesquisa. A mensuração da exogeneidade do corpo editorial de um periódico é tida como ação primordial para evitar a endogenia, o que pode acarretar fisiologismo na produção científica e enviesamento dessa produção. A avaliação da exogeneidade do corpo editorial influencia a própria cientificidade da produção veiculada pela revista, na medida em que se atribui menos credibilidade à avaliação de um artigo realizada por um colega de trabalho e/ou por um pesquisador que desacredita determinada vertente de pesquisa por razões pessoais. Dentre as sete áreas que não adotam o critério 17, apenas a área "História" adota outros critérios para avaliar a exogeneidade do corpo editorial ${ }^{5}$.

O critério 226- "Pelo menos $60 \%$ dos artigos devem ser de autores afiliados a instituições diferentes da responsável pela edição do periódico" - é adotado por nove das 18 áreas de avaliação, não sendo adotado pelas áreas: "Comunicação e informação", "Direito", "Filosofia", "Geografia", "Psicologia", "Administração", "Economia", "Planejamento urbano, regional e demografia" e "Serviço social". A avaliação da exogeneidade dos autores é uma das formas de evitar que um periódico seja utilizado como veículo de publicação para os autores da instituição que o edita e que, portanto, os autores sejam avaliados por pesquisadores da mesma instituição. Ao mesmo tempo, busca trazer à instituição editora do periódico maior variedade de pesquisas de áreas temáticas diferentes das áreas pesquisadas na instituição, fomentando, assim, a inovação.

\footnotetext{
${ }^{5}$ São critérios adotados pela área para avaliar a exogeneidade do corpo editorial: "Participação de ao menos $20 \%$ de pesquisadores estrangeiros nos conselhos" e "Corpo editorial composto por ao menos 2 pesquisadores de instituições internacionais".

${ }^{6}$ Ressalta-se que este critério foi classificado dentro do universo da pesquisa com diferentes níveis de exigência. Sendo assim, as áreas podem ser pouco exigentes em relação à exogeneidade dos autores (cobrar somente $25 \%$ ), ou serem muito exigentes (cobrar $85 \%$ ). A escolha de "Pelo menos $60 \%$ " para análise se deu somente por conta do recorte que foi feito, de repetição em ao menos nove áreas.
} 
Assim como no corpo editorial, desencorajar a endogenia dos autores de uma revista é essencial para se evitar o fisiologismo na produção científica e o enviesamento dessa produção para uma determinada área de pesquisa, bem como incentivar a inovação e originalidade das pesquisas. Das áreas que não adotam o critério aqui analisado, três delas adotam outros para avaliar a exogeneidade dos autores, são elas: "Comunicação e informação"7, "Direito"8 e "Filosofia"9. Não foram identificados outros critérios adotados pelas áreas "Geografia", "Psicologia", "Administração", "Economia", "Planejamento urbano, regional e demografia" e "Serviço social" para avaliar a exogeneidade dos autores que publicam nas revistas da área.

\section{Quadro 2 - Ranking das classes de critérios}

\begin{tabular}{|c|l|c|}
\hline № & \multicolumn{1}{|c|}{ CLASSIFICAÇÃO DOS CRITÉRIOS } & $\begin{array}{c}\text { FREQUENCIA POR } \\
\text { CLASSE }\end{array}$ \\
\hline 1 & Exogeneidade dos autores & 78 \\
\hline 2 & Bases de dados, indexadores e índices & 59 \\
\hline 3 & Informações gerais sobre política editorial & 48 \\
\hline 4 & Corpo editorial & 30 \\
\hline 5 & Número de fascículos e artigos & 28 \\
\hline 6 & Resumo & 25 \\
\hline 7 & Informações gerais sobre a revista & 25 \\
\hline 8 & Avaliação por pares & 23 \\
\hline 9 & Palavras-chave & 23 \\
\hline 10 & Tempo de publicação & 20 \\
\hline 11 & Cumprimento da periodicidade & 18 \\
\hline 12 & Exogeneidade do corpo editorial & 18 \\
\hline 13 & Métricas e estatísticas & 15 \\
\hline
\end{tabular}

${ }^{7}$ São critérios adotados pela área para avaliar a exogeneidade dos autores: "Ter pelo menos 1 autor de instituição diferente da responsável pela edição do periódico" e "Pelo menos $80 \%$ dos artigos devem ser de autores afiliados a instituições diferentes da responsável pela edição do periódico"

${ }^{8}$ Critério adotado pela área para avaliar a exogeneidade dos autores: "Publicação, por volume, de ao menos $15 \%$ de artigos de autores e/ou co-autores com afiliação estrangeira"

${ }^{9}$ Critério adotado pela área para avaliar a exogeneidade dos autores: "Ao menos 1 artigo por volume/ano deve ser de autor (es) e/ou coautor (es) afiliados a instituições estrangeiras". 


\begin{tabular}{|c|c|c|}
\hline 14 & Exogeneidade estrangeira dos autores & 14 \\
\hline 15 & Normas de Submissão & 14 \\
\hline 16 & Cobertura temática & 13 \\
\hline 17 & ISSN & 17 \\
\hline 18 & Publicações de natureza acadêmica/científica & 13 \\
\hline 19 & Afiliação dos autores & 12 \\
\hline 20 & Indicação da periodicidade & 12 \\
\hline 21 & Afiliação dos membros do corpo editorial & 11 \\
\hline 22 & Conteúdo pertinente à área da revista & 10 \\
\hline 23 & Periodicidade mínima & 10 \\
\hline 24 & Página web da revista & 9 \\
\hline 26 & Titulação e contato dos autores & 9 \\
\hline 25 & Exogeneidade estrangeira do corpo editorial & 8 \\
\hline 27 & Título & 7 \\
\hline 28 & Legenda bibliográfica & 6 \\
\hline 29 & Pareceristas & 6 \\
\hline 30 & Tipos de documentos publicados & 6 \\
\hline 31 & Identificadores persistentes & 5 \\
\hline 32 & Código de ética/Declarações de boas práticas & 4 \\
\hline 33 & Referência e citação & 4 \\
\hline 34 & Titulação dos membros do corpo editorial & 4 \\
\hline 35 & $\begin{array}{l}\text { Informações gerais sobre acesso e } \\
\text { interoperabilidade }\end{array}$ & 4 \\
\hline 36 & Publicações originais e inéditas & 3 \\
\hline 37 & Preservação digital & 2 \\
\hline 38 & Sumário & 2 \\
\hline
\end{tabular}

Fonte: Dados da pesquisa

O quadro 2 traz uma perspectiva mais abrangente acerca dos critérios de qualidade requisitados, pois apresenta as classes de critérios com maior 
frequência de ocorrência entre todas as áreas do conhecimento ${ }^{10}$. A classe que apresenta maior representatividade na amostra é "Exogeneidade dos autores", com frequência 78 , representando $12,68 \%$ da frequência total dos critérios (615). Tem-se, assim, que $12,68 \%$ do total de critérios dizem respeito à exogeneidade dos autores, permitindo inferir que boa parte das áreas de conhecimento analisadas atribuem importância aos critérios que se voltam para esta característica. Esse resultado é bastante significativo e denota o caráter ético que as publicações precisam se atentar, uma vez que a publicação majoritária de artigos escritos por autores internos à instituição editora configura-se como uma prática antiética, de maneira que a avaliação por pares entre agentes endógenos põe em dúvida a rigidez dessa avaliação. Apesar da maioria das áreas de avaliação adotarem critérios a respeito da "Exogeneidade dos autores" e de existirem 19 critérios dentro dessa classe, oito áreas não adotam nenhum desses critérios, assim como seis áreas não adotam nenhum dos 25 critérios que, somados, integram as classes "Exogeneidade dos autores" e "Exogeneidade estrangeira dos autores".

A classe com a segunda maior frequência é a classe "Bases de dados, indexadores e índices" com frequência de 59 (9.59\%) da frequência total dos critérios. A essencialidade dessa classe na visão do Qualis pode ser explicada pelo fato de que a presença em bases de dados, indexadores e índices, em geral, aumenta consideravelmente a visibilidade dos periódicos, aumentando, por conseguinte, a probabilidade de leitura e citação dos artigos e os índices bibliométricos da revista. Além disso, deve-se relacionar que boa parte dessas bases de dados, indexadores e índices exigem que as revistas cumpram certa quantidade de critérios de qualidade editorial"11. A classe "Bases de dados, indexadores e índices" é composta por 18 critérios, desses, apenas nove especificam os indexadores em que a revista deve estar presente. Os demais

10 É imprescindível deixar claro que as classes não foram extraídas dos documentos utilizados para esta pesquisa, mas foram criadas pelos próprios pesquisadores com vistas a facilitar a compreensão, agrupamento e análise dos dados de pesquisa.

11 Essa cobrança de critérios de qualidade editorial por parte de indexadores, de certo modo, força os editores e conselhos editoriais das áreas do conhecimento não vinculadas ao Colégio de humanidades a se preocuparem com essas questões. 
apenas dizem que as revistas devem estar em determinado número de bases de dados, nacionais ou internacionais. Dos nove critérios que indicam indexadores, apenas seis indicam indexadores que possuem critérios de qualidade editorial em sua avaliação, são eles: DOAJ, Latindex, Redalyc, Scielo, Scopus e Web of Science. As únicas cinco áreas que adotam pelo menos um desses indexadores são: "Comunicação e informação", "Letras, linguística e literatura", "Direito", "Planejamento urbano, regional e demografia", "Serviço social".

Fazendo uma análise mais geral das classes apresentadas, percebe-se que existem quatro classes voltadas para a avaliação dos autores: "Exogeneidade dos autores", "Exogeneidade estrangeira dos autores", "Afiliação dos autores" e "Titulação e contato dos autores". Dessas quatro, duas se voltam especificamente para a exogeneidade dos autores, o que confirma uma preocupação com a questão da endogenia como algo prejudicial para a produção científica. Já no que diz respeito à avaliação do corpo editorial foram definidas cinco classes: "Corpo editorial", "Exogeneidade do corpo editorial", "Afiliação dos membros do corpo editorial", "Exogeneidade estrangeira do corpo editorial" e "Titulação dos membros do corpo editorial". A proeminência de classes referentes ao corpo editorial demonstra preocupação tanto com uma descrição mais completa dos integrantes do corpo editorial quanto com a prevenção da endogenia entre esses integrantes. Identificam-se, também, três classes que se voltam para a periodicidade da revista: "Cumprimento da periodicidade", "Indicação da periodicidade" e "Periodicidade mínima", e duas classes que se voltam para a avaliação por pares: "Avaliação por pares" e "Pareceristas", o que denota que parte das áreas atribui importância ao cumprimento da periodicidade indicada e a realização e comprovação da avaliação por pares como práticas essenciais às revistas científicas. Ao mesmo tempo, percebe-se que existem áreas que adotam nenhum dos critérios de determinadas classes, por exemplo, as classes "Exogeneidade dos autores" e "Exogeneidade estrangeira dos autores" em que seis áreas adotam nenhum dos 25 critérios. Deste breve panorama, é possível notar certa falta de integração entre as áreas de conhecimento e influência limitada que o trabalho de uma área exerce sobre a outra, criando um quadro em que uma classe de critérios pode ser muito 
importante para algumas áreas e nada ou pouco importante para outras.

\section{CONCLUSÕES}

Considerando a análise de dados, percebe-se uma falta de integração na criação das políticas de avaliação de periódicos entre as áreas do Qualis Periódicos. Como apontado inicialmente, há uma desvalorização dos critérios qualitativos em detrimento de critérios quantitativos de avaliação, uma vez que, majoritariamente, somente as áreas que compõem o Colégio de humanidades adotam critérios qualitativos no processo de avaliação.

Nenhum dos 154 critérios de qualidade levantados neste estudo encontrase em todas as 18 áreas do Colégio de humanidades, e esse fato, quando somado ao número de critérios que atendem a apenas uma área de avaliação $(40,26 \%)$, corroboram com o indicativo de não existir grande coesão entre as áreas a respeito dos critérios de avaliação adotados. Outro indicativo dessa divergência é o da classe "Exogeneidade dos autores", que apresenta maior representatividade na amostra com frequência de 78, representando $12,68 \%$ da frequência total (615). Apesar da maioria das áreas de avaliação adotarem critérios a respeito da "Exogeneidade dos autores" e de existirem 19 critérios dentro dessa classe, oito áreas adotam nenhum dos critérios que a compõe. Essa relação se encontra em diversas outras classes apresentadas na análise de dados, de maneira que a falta de uma maior integração ou de influência de uma área sob a outra cria um quadro em que uma classe de critérios pode ser muito importante para algumas áreas e nada ou pouco importante para outras.

Os critérios que avaliam questões de cientificidade dos conteúdos publicados e a transparência e responsabilização dos processos de publicação da revista são essenciais à avaliação da produção científica. O cumprimento de critérios formais ajuda a garantir a própria cientificidade dos conteúdos publicados, se esses conteúdos estão, de fato, passando por um processo de avaliação e se esse processo está sendo realizado de forma honesta, transparente e idônea. A garantia de que determinado conteúdo publicado por uma revista é científico é atribuído pela avaliação por pares, deve-se ter, assim, 
alguma instância que garanta que essa avaliação está sendo realizada e que ela não considera somente a delimitação temática da revista, mas, também, quesitos formais, objetivos e metodológicos.

Não obstante, faz parte das questões éticas da publicação garantir que um determinado editor não está aprovando artigos de colegas de trabalho sem a rigidez exigida por uma avaliação impessoal, assim como garantir que existam responsáveis caso a revista publique resultados fraudulentos ou artigos plagiados. Nessas ponderações é que se destacam a importância dos critérios qualitativos de avaliação, uma vez que, apesar de não ser uma blindagem infalível contra essas práticas antiéticas, dificultam sua realização. Essa possível "blindagem" é claramente notada nos critérios referentes à avaliação por pares, onde pode ser exigido das revistas questões como: descrição da política de avaliação, disponibilização do formulário de avaliação ao qual o parecerista deve seguir, indicação do responsável pela decisão final de avaliação, descrição da política de conflito de interesses, publicação dos pareceres de avaliação, indicação da periodicidade de publicação dos pareceristas (dentro do que for possível e no tempo que the for confortável) etc. Esses são alguns exemplos voltados à avaliação por pares, mas existem diversos outros critérios voltados para exogeneidade do autor e do corpo editorial, das políticas editoriais e de submissão, de tecnologias voltadas para a gestão da revista que podem ser considerados como ferramentas para garantir a cientificidade da produção. No fim das contas, os critérios aqui estudados são "meta-avaliadores", responsáveis por determinar se as revistas são científicas ou não. Partindo dessas prerrogativas deve-se perguntar se é possível avaliar a produção científica brasileira sendo que parte da produção avaliada pode não estar passando pelos processos formais que garantem sua cientificidade.

O Qualis Periódicos tem como função primordial avaliar os Programas de Pós-Graduação brasileiros e, consequentemente, avaliar a ciência brasileira produzida por esses programas. Considerando esse objetivo geral, a adoção de pelo menos um núcleo básico de critérios qualitativos para a totalidade das áreas de avaliação parece ser um meio eficiente para o cumprimento desse objetivo. Diferentemente dos critérios quantitativos, em que as métricas são pautadas 
pelas especificidades das metodologias de cada área, critérios qualitativos se caracterizam, em grande parte, pela universalidade dos seus propósitos. Dizem respeito a questões gerais de comunicação científica e que perpassam todas as áreas do conhecimento. A realização de uma avaliação por pares idônea, uma produção científica livre de fisiologismo e enviesamento ideológico e a apresentação de dados e resultados de pesquisa de modo a permitir sua reprodutibilidade são anseios gerais da Ciência. Sendo assim, julga-se ser de competência primordial ao avaliador dos PPGs o estabelecimento desses critérios mínimos.

Uma barreira para a adoção de critérios de qualidade editorial está na dificuldade de realizar a avaliação revista a revista, o que poderia ser solucionado com o estabelecimento de parcerias com indexadores mundialmente reconhecidos. Entre esses indexadores, podem ser citados: Latindex, Redalyc e Scielo. Esses indexadores fazem a avaliação das revistas em diferentes níveis de detalhamento para o cumprimento dos critérios, podendo ser mais restritivos, como o Scielo, que procura não indexar revistas diferentes que se voltam para temas similares, ou inclusivos, como Redalyc e Latindex, que permitem a indexação de qualquer revista científica, bastando que cumpra os critérios de avaliação previamente definidos. Evidentemente existe uma variedade de indexadores que avaliam a qualidade editorial das revistas e que podem ser utilizados como ferramentas essenciais no processo de avaliação e certificação da cientificidade dessas revistas. $O$ fato de existirem indexadores inclusivos permite que o Qualis Periódicos exija, mesmo para extratos mais baixos da avaliação, que as revistas passem pela avaliação e comprovem que os critérios básicos de cientificidade estão sendo cumpridos.

\section{REFERÊNCIAS}

ARAÚJO, P. C. de. Motivação dos docentes do setor de ciências jurídicas da Universidade Federal do Paraná para publicar em periódicos científicos. In: ENCONTRO NACIONAL DE PESQUISA EM CIÊNCIA DA INFORMAÇÃO, 14., 2013. Florianópolis. Anais [...]. Florianópolis: Universidade Federal de Santa Catarina, 2013. Online. Disponível em: 
http://enancib.ibict.br/index.php/enancib/xivenancib/paper/viewFile/4361/3484. Acesso em: 14 fev. 2019.

ARAÚJJ, P. C. de.; MIGUEL, S. Motivações dos discentes do Programa de Pós-Graduação em Direito da Universidade Federal do Paraná (UFPR) para publicar em periódicos científicos no domínio do Direito. Perspectivas em Ciência da Informação, Belo Horizonte, v. 22, n. 1, p, 38-56, jan./mar. 2017.

BARATA, R. de C. B. Dez coisas que você deveria saber sobre o Qualis. Revista Brasileira de Pós-Graduação, Brasília, v. 13, n. 30, p, 13-40, jan./abr. 2016. Disponível em: http://ojs.rbpg.capes.gov.br/index.php/rbpg/article/view/947/pdf. Acesso em: 21 fev. 2019.

COSTA, E. H. dos S. Periódicos de acesso aberto: um canal de disseminação dos pesquisadores bolsistas PQ1A do CNPq? 2018. Tese (Doutorado em Ciência da Informação) - Escola de Comunicação, Universidade Federal do Rio de Janeiro; Programa de Pós-Graduação em Ciência da Informação, Instituto Brasileiro de Informação em Ciência e Tecnologia, Rio de Janeiro, 2018. Disponível em: http://ridi.ibict.br/handle/123456789/977. Acesso em: 13 fev. 2019.

FERREIRA, S. M. S. P. F.; MARCHIORI, P. Z.; CRISTOFOLI, F. Fatores motivacionais da comunidade científica para publicação e divulgação de sua produção em revistas/repositórios científico-acadêmicos: um estudo com grupos de autores-pesquisadores em Ciências da Comunicação e Ciência da Informação/Biblioteconomia. Relatório final de projeto. São Paulo: USP; Curitiba: UFPR, 2009. Disponível em: http://eprints.rclis.org/13616/1/Relatorio_final_Projeto_motivacao_outubro09.pdf . Acesso em: 14 fev. 2019.

SILVEIRA, D. T.; CÓRDOVA, F. P. A pesquisa científica. In: GERHARDT, T. E.; SILVEIRA, D. T. (org.). Métodos de pesquisa. Porto Alegre: Editora da UFRGS, 2009. p. 31-42. Disponível em: http://www.ufrgs.br/cursopgdr/downloadsSerie/derad005.pdf. Acesso em: 27 jun. 2019.

MUELLER, S. P. M. O círculo vicioso que prende os periódicos nacionais. DataGramaZero: Revista de Ciência da Informação, s. I., 1999. Disponível em: http://repositorio.unb.br/handle/10482/985. Acesso em: 19 fev. 2019.

NOBRE, L. N.; FREITAS, R. R. A evolução da pós-graduação no Brasil: histórico, políticas e avaliação. Revista Brasileira de Engenharia de Produção, Vitória, v. 3, n. 2, p. 18-30, 2017. Disponível em: http://periodicos.ufes.br/BJPE/article/view/v3n2_3/pdf. Acesso em: 24 jun. 2019.

OLIVEIRA, C. C. V. de. Qualidade dos periódicos científicos: um modelosíntese para avaliação com foco nos aspectos extrínsecos e intrínsecos 
indiretos da publicação. 2017. Tese (Doutorado em Gestão e Organização do Conhecimento) - Escola de Ciência da Informação, Universidade Federal de Minas Gerais, Belo Horizonte, 2017. Disponível em:

http://www.bibliotecadigital.ufmg.br/dspace/handle/1843/BUBD-AXZM69.

Acesso em: 11 fev. 2019.

PASSOS, P. C. S. J.; PASSOS, J. E.; CAREGNATO, S. E.; SILVA, T. L. K. da. Critérios de qualidade em periódicos científicos. Informação \& Sociedade: estudos, João Pessoa, v. 28, n. 2, p. 209-226, maio/ago. 2018. Disponível em: https://periodicos.ufpb.br/index.php/ies/article/view/39101/20803. Acesso em: 29 out. 2019.

ROZEMBLUM, C.; UNZURRUNZAGA, C.; BANZATO, G.; PUCACCO, C. Calidad editorial y calidad científica en los parámetros para inclusión de revistas científicas en bases de datos en Acceso Abierto y comerciales.

Palabra Clave: La Plata, v. 4, n. 2, p. 64-80, 2015. Disponível em: http://www.palabraclave.fahce.unlp.edu.ar/article/view/PCv4n2a01. Acesso em: 10 jan. 2020.

SOMA, N. Y.; ALVES, A. D.; YANASSE, H. H. O Qualis Periódicos e sua utilização nas avaliações. Revista Brasileira de Pós-Graduação, Brasília, v. 13, n. 30, p, 45-61, jan./abr. 2016. Disponível em: http://ojs.rbpg.capes.gov.br/index.php/rbpg/article/view/1128. Acesso em: 25 jun. 2019.

\title{
ANALYSIS OF FORMAL CRITERIA FOR EDITORIAL QUALITY: THE POLICY FOR CLASSIFICATION OF SCIENTIFIC JOURNALS FROM QUALIS PERIÓDICOS
}

\begin{abstract}
Introduction: Qualis Periódicos is a national system used to classify the intellectual production of Brazilian researchers linked to Postgraduate Programs (PPGs). In this sense, the relationship between the reputation of a given PPG and the stratification received by the scientific journals in which its members publish is direct. Objective: Given the importance of the classifications received by the journals, the research aims to analyze the most recurrent qualitative evaluation criteria charged by Qualis Periódicos in the classification event corresponding to the Quadrennium 2013-2016 in all areas of knowledge linked to the College of humanities. Methodology: The research is of a Qualiquantitative nature carried out based on a documentary survey. The evaluation criteria of the mentioned areas were compiled, tabulated and analyzed. Results: There is a lack of integration in the creation of journal evaluation policies between the areas of the sample, which creates a framework in which a class of criteria can be very important for some areas and nothing or not very important for others. Conclusions: The qualitative criteria are characterized by the universality of their purposes, they concern general questions of science and cover all areas of knowledge. The fulfillment of these criteria helps to guarantee the scientificity of the published contents, which makes it essential to question whether it is possible to evaluate the Brazilian scientific production, as part of
\end{abstract}


this production may not be going through the processes that guarantee its scientificity. In view of the issue, it is proposed to build a basic nucleus of qualitative evaluation criteria common to all areas.

Descriptors: Evaluation. Journal quality. Editorial quality. Qualis Periodicos. Scientific journals.

\title{
ANÁLISIS DE CRITERIOS FORMALES PARA LA CALIDAD EDITORIAL: LA POLÍTICA DE CLASIFICACIÓN DE REVISTAS CIENTÍFICAS DE QUALIS PERIÓDICOS
}

\begin{abstract}
RESUMEN
Introducción: Qualis Periódicos es un sistema nacional utilizado para clasificar la producción intelectual de investigadores brasileños vinculados a Programas de Posgrado (PPG). En este sentido, la relación entre la reputación de una PPG dada y la estratificación recibida por las revistas científicas en las que sus miembros publican es directa. Objetivo: Dada la importancia de las clasificaciones recibidas por las revistas, la investigación tiene como objetivo analizar los criterios de evaluación cualitativa más recurrentes cobrados por Qualis Periódicos en el evento de clasificación correspondiente al Cuadrienio 2013-2016 en todas las áreas de conocimiento vinculadas al Colegio de Humanidades. Metodología: La investigación es de naturaleza cualitativa cuantitativa realizada en base a una encuesta documental. Los criterios de evaluación de las áreas mencionadas fueron compilados, tabulados y analizados. Resultados: existe una falta de integración en la creación de políticas de evaluación de revistas entre las áreas de la muestra, lo que crea un marco en el que una clase de criterios puede ser muy importante para algunas áreas y nada o no muy importante para otras. Conclusiones: Los criterios cualitativos se caracterizan por la universalidad de sus propósitos, se refieren a cuestiones generales de ciencia y cubren todas las áreas del conocimiento. El cumplimiento de estos criterios ayuda a garantizar la cientificidad de los contenidos publicados, lo que hace que sea esencial preguntarse si es posible evaluar la producción científica brasileña, ya que parte de esta producción puede no estar pasando por los procesos que garantizan su cientificidad. En vista del problema, se propone construir un núcleo básico de criterios de evaluación cualitativa comunes a todas las áreas.
\end{abstract}

Descriptores: Evaluación. Calidad de revista. Calidad editorial. Qualis Periodicos. Revistas científicas.

Recebido em: 27.04.2020

Aceito em: 22.02.2021 